\title{
VIAJAR E BEBER. OS VINHOS CISTERCIENSES DE ALCOBAÇA (PORTUGAL) NA LITERATURA DE VIAGENS
}

\author{
António Valério Maduro \\ Instituto Superior da Maia - ISMAI \\ CEDTUR - Centro de Estudos de Desenvolvimento Turístico/ISMAI e CETRAD
}

\begin{abstract}
Resumo: O Mosteiro cisterciense de Alcobaça foi alvo do interesse dos viajantes ilustrados que nos séculos XVIII e XIX visitaram Portugal e permaneceram o tempo suficiente para alargar o périplo além da cintura geográfica da capital. Com esta visita procuravam apreciar a arquitectura e a arte, com relevo para os túmulos historiados de Pedro e Inês. Os viajantes de maior estatuto beneficiaram das comodidades da hospedaria monástica, da sua mesa e seus néctares. A literatura de viagens que produziram é de particular importância para avaliar as transformações arquitectónicas do edificado, sentir a vida da Abadia, seus usos, costumes e rituais, compreender a organização da paisagem produtiva. A vinha e o vinho constituem referências significativas nas descrições. São as vinhas da cerca monástica e do relego da Gafa, a grandiosidade da adega e a qualidade dos vinhos que reputam como os melhores da Europa. Palavras-chave: Alcobaça, Cister, Viagens, Vinhas, Vinhos.
\end{abstract}

Abstract: Travelling and drinking. The cistercian wines of Alcobaça (Portugal) in travel literature The Cistercian Monastery of Alcobaça was the target of interest to scholarly travelers that in the eighteenth and nineteenth visited Portugal and stayed long enough to extend the tour beyond the geographical belt of the capital. With this visit, they sought to appreciate the architecture and art, with emphasis on the tombs of Pedro and Inês, whose history was written. Travellers of a higher status benefited from the monastic hostel facilities, their table and their nectars. The travel literature they produced is of particular importance to evaluate the architectural transformations of buildings, feel the life of the Abbey, their habits, customs and rituals, understand the organization of the productive landscape. The vineyard and wine are significant references in the descriptions. It's the vineyards of the monastic enclosure and the Gafa's "relego", the grandeur of the winery and wine quality that they regard as the best in Europe.

Keywords: Alcobaça, Cistercian, Travel, Vineyards, Wine.

Resumen: Viajar y beber. Los vinos cistercienses de Alcobaça (Portugal) en la literatura de viajes El monasterio cisterciense de Alcobaça fue objeto de interés para los viajeros ilustrados que visitaron Portugal en los siglos XVIII y XIX y permanecieron el tiempo suficiente para alargar su 


\begin{abstract}
periplo más allá del cinturón geográfico de la capital. Con esta visita buscaban apreciar la arquitectura y el arte, en especial los túmulos historiados de Pedro e Inés. Los viajeros de mayor estatus se beneficiaban de las ventajas de la hospedería monástica, de su mesa y sus néctares. La literatura de viajes que produjeron es de particular importancia para evaluar las transformaciones arquitectónicas de los edificios, sentir la vida de la abadía, sus usos, costumbres y rituales, y comprender la organización del paisaje productivo. Los viñedos y el vino constituyen referencias significativas en las descripciones. Son los viñedos cercanos al monasterio y del "lagar de la Gafa", la grandiosidad de la bodega y la calidad de los vinos que reputan como los mejores de Europa.
\end{abstract}

Palabras clave: Alcobaça, Císter, viajes, viñedos, vino

1. A viagem aristocrática inserida no denominado Grand Tour conhece por meados do século XVIII uma irradiação geográfica deixando de se confinar às cidades Italianas, França, Alemanha e Holanda... A Península Ibérica começa a ser alvo da curiosidade das elites ilustradas constituindo uma alternativa ao tradicional roteiro de matriz clássica e humanista. No território português este périplo vai-se intensificar em virtude das notícias do terramoto de 1755, acontecimento que polariza as atenções da Europa culta (Gandra, 2005:7-8; Martins, 1987:34). Este abraçar das periferias traz à ribalta a dimensão comparativa, o confronto de universos culturais já que este espaço era assimilado como exótico. O bloco ibérico era encarado sumariamente como um mundo que não tinha acompanhado a modernidade carreada pelo ideário iluminista e liberal, em que a mordaça do absolutismo e do catolicismo privavam os povos e as nações de reformar as instituições e os costumes, de um desafogo da vida material, de trilhar a senda do progresso e a nova ordem da civilização (Chaves, 1983: 11-12; Outeirinho, 2002:287-288). Este preconceito ideológico e de superioridade constitui muitas vezes uma lente que desfoca o olhar de quem viaja visando em exclusivo a confirmação de uma tese de decadência e atraso para os povos que não beneficiaram da reforma religiosa e do seu espírito utilitário e estão arredados das dinâmicas científicas, técnicas e económicas patrocinadas pela revolução industrial.

Quem viaja fá-lo por prazer e ilustração. A viagem tem naturalmente um cunho propedêutico e formativo e, em certa medida, ela corresponde a um ritual de iniciação que os bons filhos de família, aqueles que podem desfrutar do ócio entendido em contraposição a uma cultura trabalho, devem praticar para se integrar em pleno na sociedade culta e elegante dos salões. Estes jovens acompanhados por um preceptor vão assim conhecer o mundo digno de ser conhecido, tornar-se cidadãos cosmopolitas (Pires, 1987:27-28; Salgueiro, 2002:291-292; San Payo, 2009:144-148).

Viaja quem pode por razão de condição social e se afoita a viajar porque a viagem responde a um tríplice afrontamento com o eu, com o outro e com o espaço (Margarido, 1987: 21). A viagem mais do que uma simbiose de olhares pode, nesta perspectiva, implicar uma mudança interior, mas nem todos os viajantes alcançavam este feito porque a modelação cultural mutilava com demasiada frequência a perspectiva.

Os viajantes que acorrem a Portugal fazem-no sobretudo por motivos de natureza diplomática, comercial, social e militar, ou por interesses específicos que se associam à benevolência climática que favorece o estanciar, a propósitos ilustrados ou ao puro prazer 
de viajar. Mas a viagem a Portugal é para muitos uma extensão da digressão por terras de Espanha, situação que facilmente se confirma nos títulos publicados (Brito, 2003:244).

Os objectivos e interesses de quem viaja estendem-se a uma pluralidade de domínios, procura-se conhecer o retrato do país, quantificar as suas gentes e recursos do território (propósitos que se irmanam com o pensamento económico fisiocrata), avaliar as instituições políticas, saber da história, da arte, da arqueologia,da literatura, da religião, dos usos e costumes e definir o carácter das populações e classes sociais, conhecer a malha urbana e as paisagens...A "viagem filosófica" estimulada pelas Academias de Ciências traz à liça os naturalistas com os seus inventários e categorias.Mas a viagem também tem o selo do prazer, de descomprometimento e nesta dimensão os testemunhos e experiências começam a ganhar o seu lugar e as impressões de viagem transmitem-nos frescos culturais de grande interesse.

2. Depois deste breve intróito sobre a filiação e âmbito das viagens vamos tratar os viajantes que na demanda a Portugal visitaram a Abadia de Alcobaça e se pronunciaram sobre as vinhas dos seus coutos, a dimensão das suas adegas e os atributos dos seus vinhos.Alcobaça não conheceu o jorro de viajantes que acudiram a Lisboa e Sintra, ou mesmo ao convento de Mafra (Gandra, 2003:244). A curta temporalidade das estadas limitou o âmbito geográfico da maior parte das visitas e parte das descrições assinaladas são importadas de outras obras consideradas referentes para a época.

Alcobaça e mais concretamente o seu Mosteiro não deixaram, todavia, de estar na rota dos viajantes mais cultos e influentes. A paragem explica-se pelo relevo que este mosteiro granjeou na história do reino de Portugal, nomeadamente a associação da sua fundação ao reconhecimento internacional do Estado português (1179), pesa ainda ter sido cabeça da Congregação Independente de Portugal (1569), o maior senhorio monástico, panteão régio,abrigar as arcas tumulares da segunda metade do século XIVde Pedro e Inês com os relevos historiados dos seus amores proibidos, em particular na roda da fortuna da cabeceira do túmulo do monarca D. Pedro I. Acresce a tudo isto ser considerado uma jóia da arquitectura gótica primeva onde em Portugal se utilizou pela primeira vez de forma sistemática as abóbadas de ogiva e os arcosbotantes (modelo de Pontigny). James Murphy ancora, aliás, o pretexto da visita ao Mosteiro na sua ligação à fundação da monarquia, à Ordem de $\mathrm{S}$. Bernardo e à introdução de uma nova arquitectura (Murphy, 1797:97).

A abadia cisterciense foi visitada por Juan Alvarez de Colmenar(1707),UdalApRhys (1749) $)^{1}$, Thomas Pitt em 1760, Richard Twiss(1773), James Murphy(1789), William Beckford (1794), Heinrich Link(1798) e William Morgan Kinsey(1827) só para mencionar alguns dos viajantes mais notáveis e ilustrados. Este périplo não cessou com o decreto de extinção das Ordens religiosas de 24 de Maio de 1834 e a Abadia continua a ser procurada como objecto patrimonial, arquitectónico e referente cultural. É o caso das visitas de Ma-

1 É muito provável atendendo ao factual do texto e à ausência de elementos descritivos espontâneos que Rhys nunca tenha visitado o mosteiro, aliás este autor foi acusado de descrever os lugares sem nunca os visitar. 
ria Rattazi(1879), de Ernest Bergman (1889), de Germond Lavigne(1890), de madame Adam (1896), de Eugene Galois(1898)...

Nas visitas anteriores ao termo das ordens religiosas masculinas em Portugal, aquelas que verdadeiramente podem observar a fábrica do mosteiro e o pulsar da vida económica do seu domínio são vulgares as referênciasàs terras de vinha, às instalações vinárias, além de delicados louvores aos vinhos monásticos.

A qualidade dos vinhos produzidos pelos cistercienses de Alcobaça já tinha sido reconhecida por Gil Vicente, no auto do "Pranto de Maria Parda":

"Item mais mando fazer

um espaçoso esprital

que quem vier de Madrigal

tenha onde se acolher

E do termo de Alcobaça

Quem vier dêem-lhe em que jaca" (Vicente, 1955: 242).

As vinhas abundavam no domínio alcobacense, o que não é de estranhar dado que a vinha é uma cultura seminal da civilização mediterrânica que, a par do olival e do trigo, constitui o fundamento da dieta alimentar destes povos. De facto, a fronteira entre a civilização e a barbárie testa-se no consumo de alimentos cozinhados, no pão e no vinho e é com estes alimentos que se avalia a condição dos povos descobertos nas navegações como o demonstra a Carta de Achamento do Brasil de Pêro Vaz de Caminha ao rei D. Manuel (Caminha, 1974:41).

Nas terras de Alcobaça as vinhas generosas no fruto e no licor estavam distribuídas nas cercanias do mosteiro como observa Thomas Pitt nas Observações de uma Viagem a Portugal e Espanha (1760), onde pontifica o relego da Quinta da Gafa, magnífica tapada que confina com a cerca de dentro e de fora do próprio mosteiro, nas colinas de suave pendor de Aljubarrota e Évora de Alcobaça (Pitt, 2006:106).Na própria cerca do Mosteiro, o Marquês de Fronteira e Alorna na visita realizada em 1824 depara-se, a par de laranjais, pomares e hortas, com "uma extensa e boa vinha, da qual tivemos provas no excellente vinho que nos forneceram à comida..." (Barreto, 2003, 425).

As vinhas e os pomares tomavam preferencialmente as ladeiras banhadas pelo sol deixando os vales para cereais e culturas hortícolas.As vinhas eram purgadas de árvores de fruto e cereais praganosos (com a excepção destes serem segados em verde para ração do gado) a fim de minimizar os efeitos do ensombramento e de contágio de pragas. A vinha estreme e compassada era protegida da acção danosa das alfaias de tracção animal como arados e charruas, cujo trânsito nas lavras podia danificar a estrutura radicular. As terras de vinha do Mosteiro eram ainda preservadas da intrusão de gados e o calendário da vindima diferenciava brancas e tintas, sendo as castas brancas as primeiras a ser vindimadas (Maduro, 2007:251).

3. William Beckford na segunda estada que faz a terras lusas nos anos de 1793 a 1794 colige um diário denominado Recollections of an Excursion to the Monasteries of 
Alcobaça e Batalha. Nesta visita demorou-se em Alcobaça entre 7 a 11 de Junho de 1794. $\mathrm{O}$ aristocrata menciona que entre a sua comitiva a rendição aos primores do vinho produzido nas adegas do Mosteiro era absoluta. Nota, aliás, o insólito comportamento do seu cozinheiro francês quando "na exaltação do momento, declarou, nada patrioticamente, que o Clos de Vougeot (refere-se a uma das mais célebres granjasvinhateiras cistercienses da Borgonha) era uma zurrapa comparado com o Aljubarrota - divino, etéreo, perfumado Aljubarrota!". E na hora da despedida do convento bernardo Beckford vê frustrada a tentativa de lançar sobre os companheiros de viagem alguma sorte de reflexão sobre a gesta lusitana. " - Mas o presente, e umas tantas garrafas de excelente vinho, produto das cepas da região, prendiam-lhes toda a atenção. - «Muito bom, primoroso, excelente», eram as únicas palavras que escapavam dos seus lábios agradecidos” (Bekford, 1997:49).

O cenóbio alcobacense na pena ilustrada de Beckford é acusado de se ter transformado no "mais notável templo de glutonaria de toda a Europa" superior ao observado nos conventos de França, Itália e Alemanha, em que os prazeres terrenos da comida e da bebida se tinham sobreposto irremediavelmente ao edificante princípio do mosteiro como uma máquina de produção de santidade.

Figura 1: Cozinha setecentista do Mosteiro de Alcobaça

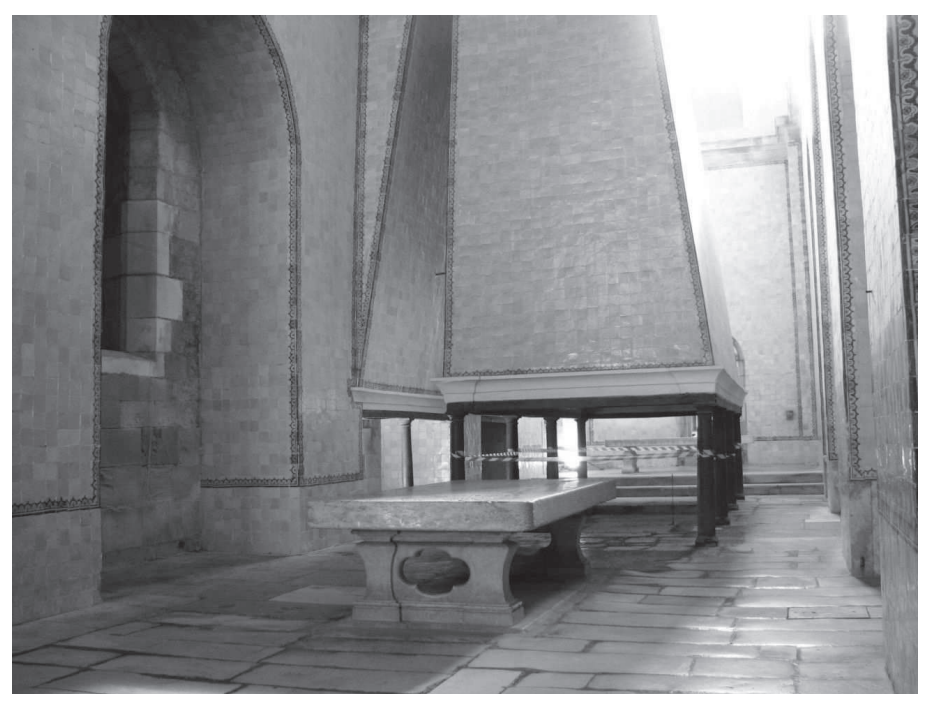

Veja-se a descrição dos víveres dispostos na soberba cozinha: "Ao centro desta imensa divisão magnificamente abobadada, de diâmetro não inferior a sessenta pés, corre um alegre regato de água claríssima que alimenta viveiros perfurados, de madeira, com os mais belos peixes do rio, de toda a espécie e tamanho. De um lado, amontoava-se grande quantidade de carne de veado e caça, do outro, legumes e fruta de toda a espécie. A seguir a uma fila de lareiras, estendia-se outra de chaminés, e nas mesas via-se farinha de trigo em montes, branca como neve, pilhas de açúcar, potes do mais puro azeite e grande fartura de massas... (Beckford, 1997:36). 
A atraente corrupção induzida pelo vinho não era um exclusivo cisterciense.Na digressão à Batalha no dia 8 de Junho, Beckford refere que um monge dominicano: «Estimulado por amplas libações do melhor vinho Aljubarrota alguma vez produzido, que previdentemente trouxéramos connosco, exclamou voluptuosamente: "Ora assim é que devia ser sempre"» (Bekford, 1997:50). Idêntico cenário é retratado por Lantier quando em Espanha visita o mosteiro Beneditino de Montserrat:"Vi que esos buenos padres estaban muy unidos al culto de la Virgen; mas no descuidaban el de Baco" (Plasencia, 2010:78).

As Memórias Paroquiais de 1758 alusivas a Aljubarrota confirmam a excelência do vinho produzido nas ladeiras desta vila dos coutos. Diz-se que "Os fructos da terra que os moradores da villa Aljubarrota recolhem em mayor abundancia são excellentes trigos, bons azeytes e milhores vinhos, e muitas e admiravens fructas de que o o seu território hé muito fecundo e copiozo principalmente de peras e maçans de muitas e diversas qualidades, as quais mais deliciozas, especialmente as camoezas, que entre todas as partes do Reyno; logram as deste fértil país a primazia, tanto pela particularidade do gosto como pela suavidade do cheiro" (Cosme; Varandas, 2011, 14). Estes peros eram utilizados nas temperanças vinárias dadas nas caves monásticas para frutar os vinhos conferindo-lhes um paladar fresco e aromático.

Mas de que tipo de vinho falava o ilustre conviva, qual o seu fabrico e o porquê dos copiosos laudatórios que sobre ele se tecem (Maduro, 2011:447-458).

No povoamento vinhateiro medieval privilegiam-se as castas brancas (galega, arinto, azal) sendo as tintas (castelão, mourisco) exclusivamente relegadas para cobrir os vinhos brancos (Gonçalves, 1989:84-86) dado a inexistência na comarca de bagas de sabugueiro para tintura ${ }^{2}$. Basicamente o povoamento devia comportar aproximadamente $80 \%$ de castas brancas, das quais o Mosteiro exigia o quinto e o dízimo, isentando, em contrapartida, as tintas destinadas a curtimenta (apenas os excedentes seriam tributados na eira).

Jean-Louis Flandrin elucida-nos que os vinhos brancos e os claretes ou palhetos estavam para o pão alvo como os retintos para o pão de segunda (Flandrin, 2001:202203). A cor agia como indicador de posição social, sendo os vinhos retintos (conhecidos por negros) e adstringentes impróprios para o paladar requintado das Ordens elevadas. Já para o povo o vinho vermelho (quanto mais coberto possível) era considerado um alimento, em substância muito superior aos brancos e assim condizente com a condição do trabalho manual. Para escurecer os seus vinhos (que por razões de lagarádiga não podiam ser elaborados de curtimenta) era prática natural deitarem-lhes bagas de sabugueiro ou na sua falta amoras silvestres.Isto não implica, no entanto, uma rejeição cabal dos vinhos vermelhos, produto que os Cancioneiros medievais exaltavam pela sua excelência. Gil Vicente aconselha a propósito que para as boas refeições "muitos bons vinhos, vermelhos" (Oliveira, 2011: 92-93). As próprias Ordens religiosas não se furtavam ao consumo de vinhos vermelhos. No inventário da Ordem de Avis (1366) menciona-se que na sua adega existiam 23 tonéis de vermelhos e rosetes e 4 de branco (Arnaut, 2000:28). Pode-se, toda-

2 Biblioteca Nacional de Portugal, códice 1493, fl.52. 
via, aceitar que os vermelhos consumidos fossem nestes casos mais claros que o costume, mas a distinção entre estes vinhos já era clara desde a Idade Média e os manuais agrícolas setecentistas comprovam estas diferenças (Alarte, 1712:192-194).

William Beckford nas variadas menções à gastronomia aristocrática e conventual que inclui no seu Diário refere os vinhos claretes, que já desde a medievalidade tinham ganho notoriedade no estrangeiro (Marques, 1981:16), a que acrescenta o Porto e o Madeira (Beckford, 2009:110, 134). A própria cerimónia ritual da Eucaristia pedia um vinho de missa mais claro que o sangue de Cristo para não tornar ainda mais pungente e dramático o acto religioso, facilitar a limpeza dos sanguíneos e não conspurcar os paramentos litúrgicos (S/A, 2003:71). De facto, a partir da Idade Média abandona-se a utilização do vinho tinto nestas práticas cerimoniais, dando lugar ao branco e ao rosete(Dias, 2002:179-180).

A tradição de quebrar o vinho com água (Marques, 1981:16-17; Arnaut, 2000:34) temperando-lhe o grau vai-se perder gradualmente e, no século XVIII, a nobreza portuguesa só consome vinhos puros como testemunha o viajante inglês Thomas Cox na sua Relação do Reino de Portugal de 1701, enquanto o povo por tradição e economia continua a verter água no vinho (o vinho terçado ou meado seguindo a receita medieval) e a ser parco no seu consumo, no que se irmana com o espanhol (Cox, 2007:276-277; Plasencia, 2010:44-45). A sobriedade do povo português é realçada pelos diversos viajantes que encaram esta disposição como uma virtude e contenção natural.

Os vinhos que deliciam a comitiva de Beckford ou o Marquês de Fronteira e Alorna são vinhos rosetes (apropriados às cerimónias litúrgicas - um vinho de missa ou do Senhor) produzidos sob o sistema de bica aberta, pisando-se as uvas e sangrando-se de imediato o mosto. A exclusividade desta técnica de vinificação não se pode dissociar do regime de monopólio imposto pelo Mosteiro que impedia aos colonos e rendeiros dos seus coutos o uso do lagar por mais de 24 horas, o que obstava naturalmente a feitura de vinhos de curtimenta (Estrela, 2001:196). As uvas tintas e brancas fermentavam à parte. Depois de terminada a fermentação dos tonéis do branco e dada a primeira trasfega adicionavam-se as tintas confeccionadas de curtimenta que assim tingiam os vinhos. Estes vinhos pouco se toldavam, mas caso isso viesse a suceder eram limpos com sangue de boi e claras de ovos ${ }^{3}$.

Para adubar, fortalecer, conservar e aromatizar o vinho juntavam-lhes arrobe, geleia de mosto numa proporção de meio almude para um tonel de duas pipas, método já utilizado por romanos, fenícios e cartagineses e prática obrigatória para os vinhos que deviam ser embarcados (o arrobe ao elevar o grau alcoólico salvava os vinhos da queima e além disso prescindia da aguardentação, de referir que a comarca de Alcobaça nos finais do século XVIII não chegava a produzir uma pipa de aguardente). Para estes fins acrescentavam ainda aos seus vinhos folhelho torrado, cascas de laranja e camoesas que podiam ser assadas com açúcar ${ }^{4}$.

3 B.N.P., códice 1490 , fl.52.

4 B.N.P., códice 1490 , fl.52 
O resultado de todas estas caldeiradas que se juntavam ao vinho para contributo de cor, aroma e paladar resultava num vinho clarete, frutado, não adstringente, graduado e até espirituoso.

Segundo Vandeli na comarca de Alcobaça também se produzia vinho de feitoria com a pisa e fermentação conjunta de castas brancas e tintas, vinhos menos subtis que se destinariam ao embarque (Vandeli, 1813:71-72).

O fabrico e a conservação dos vinhos do Mosteiro era feito integralmente em vasilhame de madeira, nomeadamente em grandes tonéis arcados de pau e ferro. Como sustenta Orlando Ribeiro tanto as talhas como os potes cerâmicos para guarda de vinhos e azeites filiam-se na matriz cultural e histórica do mediterrâneo das civilizações clássicas, isto não invalida o conhecimento por parte dos romanos do vasilhame de madeira (Brochado, 2006:403-404), enquanto a vasilha de aduelas constitui uma herança do norte europeu (Ribeiro, 1979:51). Entre as madeiras utilizadas nas suas adegas é mencionado o castanho e o choupo. $\mathrm{O}$ choupo madeira fraca para préstimos vinários seria utilizada preferencialmente para receber os vinhos correntes de pronto consumo, enquanto o castanho arrecadaria os vinhos que pelo seu carácter podem estagiar e envelhecer sem receio de deterioração.

Figura 2: Antiga Sala dos Monges na Idade Média utilizada como adega na $2^{\mathrm{a}}$ metade do século XVIII

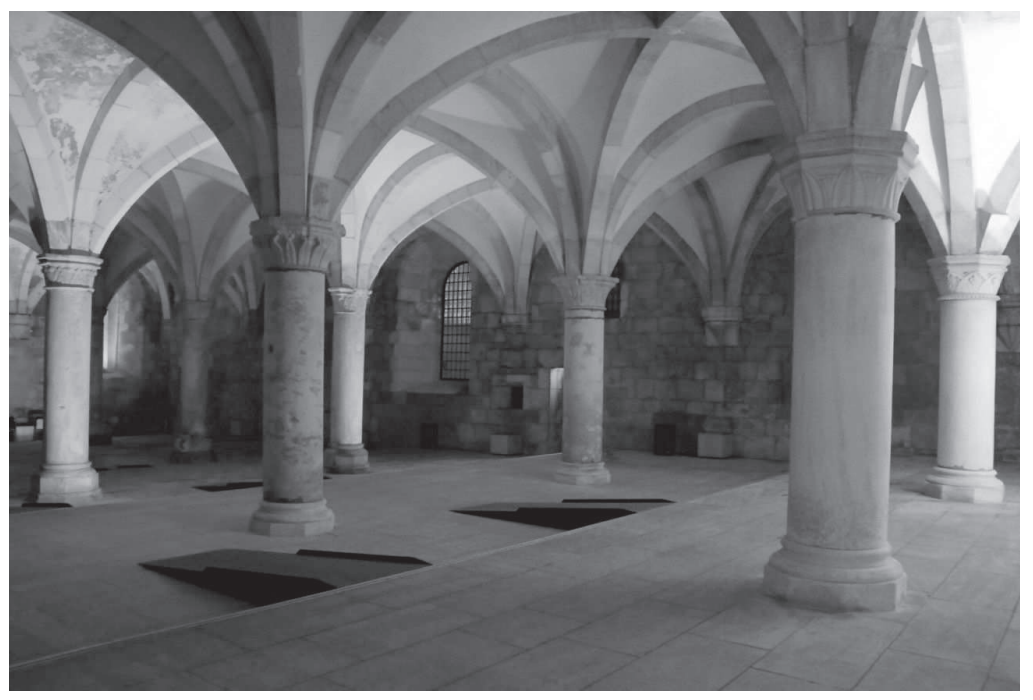

O Mosteiro possuía 18 adegas disseminadas no território dos Coutos $^{5}$. Paradoxalmente havia pouco cuidado na sua edificação. Esta despreocupação quanto à natureza do local de assento e à busca de rumos adequados que protegessem os seus vinhos da ardente

5 Referem-se adegas em "Alfeizerão - 1; Aljubarrota - 1; Alvorninha - 1; Quinta do Castelo - 1; Santa Catarina -2 ; Cela - 1; Évora - 1; Famalicão - 1; Quinta da Gafa - 1; Julgado - 1; Maiorga - 1; Salir de Matto - 1; Quinta de Turquel, e Villa - 2; Vallado, e Quinta - 2; Quinta do Vimeiro - 1”. B.N.P., códice1493, fl.44. 
canícula, ou do agreste soão, contribuiria provavelmente para agravar os problemas de conservação ${ }^{6}$. Mas este cenário não dizia respeito à adega do próprio Mosteiro.

A dimensão das adegas dos mosteiros faz pasmar os viajantes. Já Munzer na relação da viagem em finais de quatrocentos que faz ao mosteiro de Poblet refere que: "No vi jamás tantas y tantas y tan grandes vasijas como las que tienen en las bodegas; en una de estas conté hasta 17, y hay algunas en que caben 30 carros"(Plasencia, 2010:77). Exagera por certo o autor, mas a descrição apresentada visa ilustrar a grandeza destas instalações.

Voltando a Alcobaça o espanto e admiração dos viajantes repetem-se face à dimensão das instalações vinárias.

Conhecemos a capacidade de armazenamento da adega da Quinta da Gafa, a maior propriedade de vinha do Mosteiro. Entre os 12 tonéis da sua adega e lagar compreendia 36 pipas. Os tonéis de maior dimensão atingiam a notável capacidade de 5 pipas?

Thomas Pitt fala-nos que a produção vinhateira almudada na adega do Mosteiro em 1760 ascendia a 300 pipas (Pitt, 2006:124). Mas a capacidade de arrecadação da adega monástica era superior como o confirma o relato da visita de James Murphy em 1789:

“Je ne dois point oublier de faire mention du cellier qui n'est pas la plus petit pièce du monastère. Il renfermait quarente énormes tonneaux, contenant sept cents barriques de vin» (Murphy, $1797: 101)$.

Esta informação é posteriormente replicada por William Kimsey na visita de 1827:

The cellar is a noble vaulted apartment, and contain some enormously large tuns, the woole of which are saíd to hold nearly seven hundred pipes of wines" (Kinsey, 1829:447).

É também provável que se tenha verificado uma expansão da área de vinha dos coutos de Alcobaça durante o século XVIII, situação consentânea com a tendência geraldo país. Basta referir que em 1839, seis anos depois de os monges terem abandonado a Abadia, a produção da comarca de Alcobaça atingia as 4000 pipas das quais se exportava cerca de um terço ${ }^{8}$. Os vinhos de Alcobaça eram consumidos em Leiria, Santarém e Tomar.

O consumo do vinho entre as comunidades monásticas era elevado (Moulin, 1987:110-120). A ração de vinho consumida pelos cistercienses de Alcobaça nos alvores do século XVI era estimada em dois litros diários por cabeça (Gomes, 2009:54). Por seu turno o "Regimento sobre alimentação e vestuário..." de 1789 aponta -"Que se dará a cada religiozo hum quartilho de vinho ao jantar, e outro ácea; e nos dias de almoço para o mesmo, meio quartilho" (Mota, 1990:282).

O Marquês de Fronteira e Alorna espanta-se com a capacidade dos copos em que se derramavam os cântaros de vinho que na sua opinião chegavam à meia canada (Barreto, 2003:425).

6 B.N.P., códice 1493, fl.52.

7 Arquivo Distrital de Leiria, Mosteiro de Alcobaça, cx.5, doc.1, Inventário dos bens móveis.

8 A.D.L., Governo Civil, Agricultura - cx.8 (1834-1859), Reflexões sobre a Indústria Agrícola do Concelho de Alcobaça (1839). 
O vinho podia ser consumido na primeira parte da refeição ou na segunda. É o Simpósio que Beckford alude no banquete que lhe foi ofertado pelo abade de Alcobaça, em que o vinho acompanha doces, frutas e frutos secos (Pires, 1987:156-157). O hábito de acompanhar as frutas com vinho como refeição ligeira apropriada para a noite é aliás mencionado nas crónicas medievais de D. Pedro e D. João I (Marques, 1997:37).

Mas atendamos ao magnífico fresco da refeição com que foi agraciado Beckford. "O banquete propriamente dito compunha-se não só do que há de melhor da cozinha tradicional, mas também de iguarias raras e especialidades fora de época e de países longínquos: enchidos deliciosos, lampreias em conserva, manjares exóticos dos Brasis, e outros da China ainda mais estranhos (ninhos de andorinha comestíveis e barbatanas de tubarão), confeccionados à moda de Macau por um irmão leigo chinês. Quanto a doces e frutas, não era aqui o seu lugar; esperavam-nos numa sala adjacente, ainda mais espaçosa e sumptuosa, onde os eflúvios das iguarias e molhos não nos alcançavam” (Beckford, 1981:14).

\section{Figura 3: Refeitório do Mosteiro de Alcobaça}

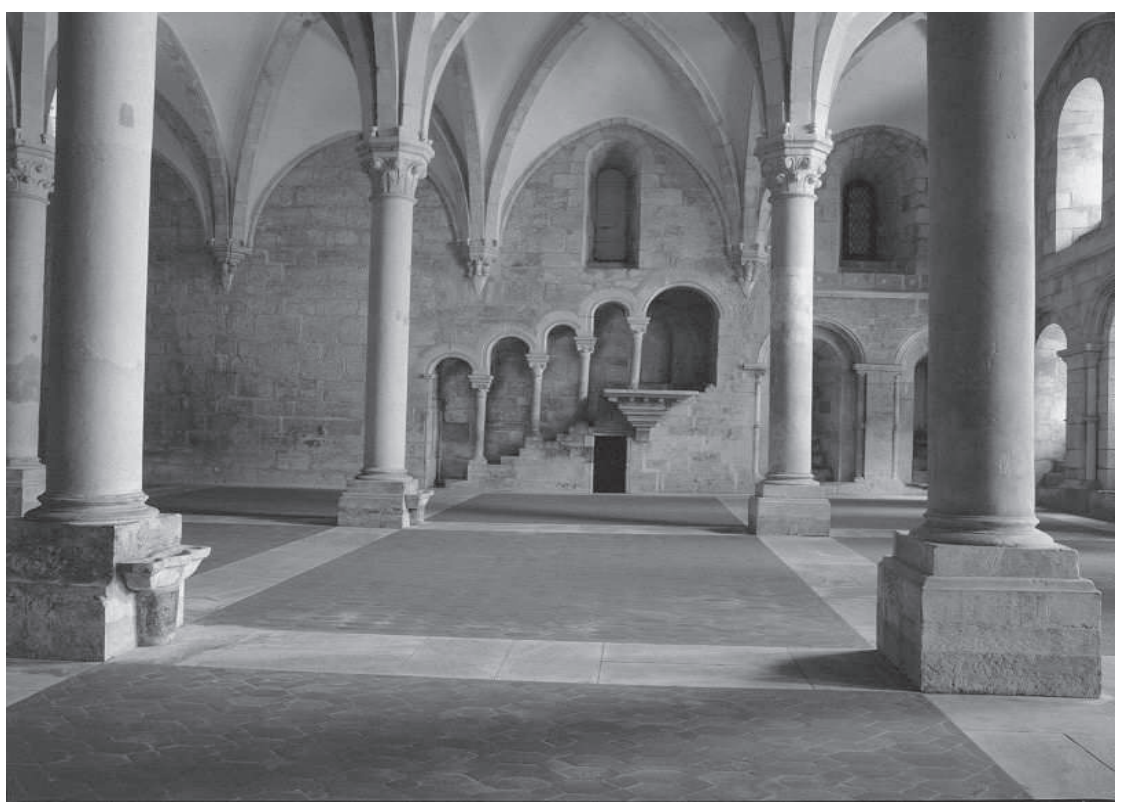

A abolição das Ordens Religiosas não teve impacto directo na cultura da vinha e no fabrico do vinho, transferindo-se esta propriedade e meios de produção para um conjunto de notáveis que arremataram os bens em hasta pública. O termo da herança cisterciense em matéria vitivinícola só ocorre com a catástrofe introduzida pelo oídio que ao alterar radicalmente o povoamento vinhateiro faz vingar a vinificação de curtimenta em detrimento da de bica aberta. Mas os vinhos de Alcobaça, mesmo depois do surto filoxérico de 1887, continuam a merecer reconhecimento nacional e internacional, sendo agraciados com medalhas nos certames da Tapada da Ajuda (1884) e na Secção Agrícola da Exposi- 
ção Industrial Portuguesa (1888),na Exposição Universal de Paris (1900), na Exposição do Rio de Janeiro (1909)... São estes bons vinhos de pasto que vão ser servidos no banquete oferecido na Sala do Capítulo do Mosteiro aos cem participantes do IV Congresso de Turismo (1911) que visitaram a região, servindo-se os licorosos a acompanhar as antigas receitas de doçaria conventual, em que pontuam as queijadas do Bárrio, o pão de ló de Alfeizerão e o arroz doce de Alcobaça.

\section{BIBLIOGRAFIA}

\section{LIVROS:}

Alarte, Vicencio (1712): Agricultura das Vinhas..., Lisboa, 1712.

Arnaut, Salvador Dias (2000): A Arte de Comer em Portugal na Idade Média, Colares Editora.

Barreto, D. José Trazimundo (2003): Memórias do Marquês de Fronteira e Alorna, vol.I-II, Lisboa, Imprensa Nacional - Casa da Moeda.

Brito, Sérgio Palma (2003): Notas sobre a evolução do viajar e a formação do turismo, vol.I, Lisboa, Medialivros.

Beckford, William (1997): Alcobaça e Batalha. Recordações de uma Viagem. (Introdução, tradução, e notas de Iva Delgado e Frederico Rosa). Lisboa, Vega.

Beckford, William (2009): Diário de William Beckford em Portugal e Espanha, Lisboa, Biblioteca Nacional de Portugal.

Caminha, Pêro Vaz (1974): Carta a el-rei dom Manuel sobre o achamento do Brasil (1 de Maio de 1500), Lisboa, Imprensa Nacional - Casa da Moeda.

Chaves, Castelo Branco (1983): Os Livros de Viagens em Portugal no século XVIII e a sua projecção europeia, Lisboa, Instituto de Cultura Portuguesa.

Cocheril, D. Maur (1961): William Beckford et la cuisine d'Alcobaça, Porto.

Cosme, João; Varandas, José (2011): Memórias Paroquiais (1758), vol. III, Lisboa, Caleidoscópio.

Flandrin, Jean-Louis (2001): História da Alimentação 2 Da Idade Média aos tempos actuais, Lisboa, Terramar.

Gandra, Manuel (2005): O Monumento de Mafra: visto por estrangeiros (1716-1908), Mafra, Câmara Municipal.

Gomes, Saul António (2009): Vinhos e História na Alta-Estremadura entre os séculos XII e XVI, Leiria, CEPAE.

Gonçalves, Iria (1989): O Património do Mosteiro de Alcobaça nos séculos XIV e XV, Lisboa, Universidade Nova de Lisboa.

KINSEY, William Morgan (1829): Portugal Illustrated, London.

Maduro, António Valério (2011): Cister em Alcobaça. Território, Economia e Sociedade (séculos XVIII-XX), Porto, ISMAI.

Marques, A. H. de Oliveira (1981): A Sociedade Medieval Portuguesa, Lisboa, Sá da Costa. 
Martins, Isabel Oliveira (1987): William Morgan Kinsey - Uma Ilustração de Portugal, Lisboa, Edições 70.

Moulin, L. (1987): La vie quotidienne des religieux au Moyen Age X-XV siècle, Paris, Hachette.

Murphy, James (1797): Voyage en Portugal, Paris.

Oliveira, Aurélio de (2011): Auto do Vinho - Mestre Gil, Resende e Miranda com os Vinhos em Bolanda, Viana do Castelo.

Pires, Maria Bettencourt (1987): William Beckford e Portugal, Lisboa, Edições 70.

Pitt, Thomas (2006): Observações de uma Viagem a Portugal e Espanha (1760), Lisboa, IPPAR.

Plasencia, Pedro (2010): Los Vinos De España Vistos Por Los Viajeros Europeos, Madrid, Miraguano Ediciones.

Ribeiro, Orlando (1979): Geografia e Civilização, Lisboa, Livros Horizonte.

S/A (2003): Libro y regístro de la bodega delMonasterio de Guadalupe, Mérida, Bodegas ViñaExtremenã (trancripção e prólogo de Arturo Álvarez).

San Payo, Manuel (2009): O Desenho em viagem...Universidade de Lisboa

Vandeli, Alexandre (1813): Resumo da Arte da Distillação, Lisboa, 1813.

Vicente, Gil (1955): Obras Completas, vol.VI, Lisboa, Sá da Costa.

\section{ARTIGOS EM REVISTAS:}

Dias, Geraldo Coelho (2002): "Um senhor vinho para o Vinho do Senhor. O fabrico e comercialização dos vinhos de missa”, Douro Estudos \& Documentos, vol VII (13), $2002\left(3^{\circ}\right)$.

Maduro, António Valério (2007): “"A cultura do olival e da vinha, motor do desenvolvimento agrário alcobacense", Separata da Revista de História da Sociedade e da Cultura (séculos XVIII-XIX)”, 7, Universidade de Coimbra.

Mota, Salvador Magalhães (1990): "O Regime Alimentar dos Monges Bernardos no Final do Século XVIII”, Separata da Revista de Ciências Históricas, 4, Universidade Portucalense.

Outeirinho, Fátima (2002): “A Viagem a Espanha. Em torno de alguns relatos de viagem oitocentistas"”, Revista da Faculdade de Letras, XIX, Universidade do Porto.

Salgueiro, Valéria, (2002): “Grand Tour: uma contribuição à história do viajar por prazer e amor à cultura", Revista Brasileira de História, V 22, 44.

\section{CAPÍTULOS DE LIVROS:}

Brochado, Carlos (2006): “O Cultivo da vinha na Antiguidade Clássica”, em História do Douro e do Vinho do Porto, vol.1.

Estrela, Jorge (2001): "Vinho Senhorial e Vinho Popular na Alta Estremadura Medieval", em $O$ Vinho, a História e a Cultura Popular, Lisboa, Instituto Superior de Agronomia.

Margarido, Alfredo (1987): “Introdução”, em Teixeira de, PascoaesO Bailado, Lisboa, Assírio \& Alvim. 